\title{
Memória, Imagem e Arquivo: a potência arquivística da ficção de Décio Pignatari
}

Memory, Image and Archive: the archival potency of Décio Pignatari's fiction

Henrique Júlio Vieira UFB 
Este texto analisa a expressão de uma potência arquivística em O rosto da memória (2014 [1986]) e Panteros (1992), do escritor Décio Pignatari, tendo como ponto de partida os pressupostos da teoria literária, da psicanálise e da bibliografia dos textos. Analisa-se a atualização de procedimentos do concretismo brasileiro por essas duas obras literárias, situadas no contexto de valorização das narrativas autobiográficas e memorialísticas a partir da década de 1980, observando-se o modo pelo qual a inserção de documentos arquivísticos à materialidade dos livros acentua a natureza autoficcional dessas narrativas.

Palavras-chave: Décio Pignatari; poesia concreta; potência arquivística; autoficção

\section{Abstract}

This text analyzes the expression of an archival potency by Décio Pignatari's fictions, in his books O rosto da memória (2014 [1986]) and Panteros (1992), having as a starting point the assumptions of literary theory, psychoanalysis and bibliography of texts. The updating of literary procedures of the Brazilian concretism by these two fiction books is analyzed, considering the context of valuing of the autobiographical and memorialistic discourses from the 1980s onwards, observing how the insertion of archivistic documents into the materiality of these books accentuates the self-fictional nature of the narratives.

Keywords: Décio Pignatari; concrete poetry; archival potency; self-fiction 
Entre as décadas de 1950 e 1960, a poesia concreta brasileira se projetou como uma vanguarda que visava a ampliar o repertório de linguagens e referências culturais da literatura feita no Brasil. Durante esse período, os textos críticos, manifestos e poemas de Décio Pignatari, Augusto e Haroldo de Campos afirmaram o traço diferencial do movimento em relação à tradição lírica dos poetas brasileiras, na contramão de sintagmas como "subjetivismo", "cor local", "lirismo" e "versificação". Os concretistas também deram um passo à frente dos seus predecessores imediatos, a geração paulista de 1922, no que se refere ao experimentalismo com a forma literária, criando relações intersemióticas com linguagens popularizadas nos anos 50, como o cinema, a publicidade, o design gráfico, a arquitetura e a música experimentais. ${ }^{1}$

O conjunto de ensaios e manifestos representativos de suas ideias encontramse reunidos na Teoria da poesia concreta. Dentre eles, um dos textos, assinado pelos três poetas, é uma espécie de súmula das táticas da "guerrilha artística" do trio no território da cultura brasileira. Trata-se do plano-piloto para a poesia concreta, publicado na revista noigandres (n. 4, ano 1958). A alusão ao projeto urbanístico da nova capital do país ambienta a atmosfera nacional-desenvolvimentista estimulado pelo presidente Juscelino Kubitschek nos idos de 1950. O plano-piloto do concretismo esquadrinhou as clareiras que seriam abertas na arte e na literatura, como aquelas mesmas que estavam sendo feitas por uma legião de operários e candangues para assentar Brasília no Planalto Central, sob a regência do arquiteto e urbanista Lúcio Costa, com a prestimosa colaboração de Oscar Niemeyer:

1 Alfredo BOSI, em História concisa da literatura brasileira, 2006, p. 439, traça o seguinte panorama: “Os melhores poetas da segunda metade do século têm respondido de modo vário aos desafios cada vez mais prementes que a cultura e a práxis lançam ao escritor. E que se chamam, por exemplo, guerra fria, condição atômica, lutas raciais, corrida interplanetária, neocapitalismo, Terceiro Mundo, tecnocracia... E, vindos embora, em sua grande parte, do formalismo menor e estetizante que marcou o clima de 45 , lograram atingir um plano mais alto e completo de integração, de que são exemplos os poderosos poemas de Ferreira Gullar e de Mário Faustino, os elaborados experimentos da poesia concreta (Haroldo de Campos, Augusto de Campos, Décio Pignatari, José Lino Grünewald, José Paulo Paes, Pedro Xisto...) e da poesia-práxis (Mário Chamie), além de todo o itinerário do maior poeta brasileiro de nossos dias, João Cabral de Melo Neto". Situando o percurso da poesia concreta particularmente, o historiador da literatura pontua: "O grupo de base já aparece coeso na antologia pré-concreta Noigandres I (1952) em que há poemas, ainda em verso, de Haroldo de Campos, Augusto de Campos e Décio Pignatari, escritores cujas obra de estreia têm ainda um ou outro ponto de ligação com o formalismo de 45. Preciosismo verbal, amplo uso dos metros tradicionais, imagética frondosa são traços de O Carrosel (S. Paulo, 1950), de Décio Pignatari, de Austo de Possesso (1950), de Haroldo de Campos e de O Rei menos o Reino, de Augusto de Campos (1951); em todos, porém, uma desenvoltura auto-irônica e um maior desembaraço no trato de motivos eróticos já diziam das suas diferenças em relação à poesia de 45 . Diferenças que logo se aprofundam, na medida em que o grupo se põe a pesquisar numa linha de sintaxe espacial abandonando polemicamente o verso: é o que se vê nas antologias de Noigandres $n^{\circ} 2$ (1955), $n^{\circ} 3$ (1956) e no 4 (1958)." (p. 475-476).

2 PIGNATARI, Décio. Contracomunicação, 2004a, p. 168. 
poesia concreta: produto de uma evolução crítica de formas. dando por encerrado o ciclo histórico do verso (unidade rítmico-formal), a poesia concreta começa por tomar conhecimento do espaço gráfico como agente estrutural. espaço qualificado: estrutura espaciotemporal, em vez de desenvolvimento meramente temporístico-linear. daí a importância da ideia de ideograma, desde seu sentido geral de sintaxe espacial ou visual até o sentido específico (fenollosa/pound) de método de compor baseado na justaposição direta - analógica, não lógico-discursiva - de elementos. "il faut que notre intelligence s'habitue à comprendre synthético-idéographiquement au lieu de analytico-discursivement' (apollinaire). eisenstein: ideograma e montagem ${ }^{3}$.

Contrariando uma tradição lírica o desbordamento e do intimismo, a criação poética era entendida como o espaço da antissubjetividade. Em uma espécie de textosíntese dessa questão, Pignatari, no ensaio construir e expressar, declarava superada a poesia como espaço do desbordamento: "Tudo isto não indica outra coisa senão que: a vontade de construir superou a vontade de expressar, ou de se expressar" ${ }^{2} .5$

Pressupondo um leitor de literatura operário e urbano, Décio Pignatari, com a assertividade que lhe era peculiar, defendia: "O operário quer um poema racional, que lhe ensine a agir e pensar como a máquina lhe ensina - e se gosta de rosas, há de preferilas reais, que as alegóricas já tão felizmente mortas em sua sensibilidade positiva" ${ }^{\text {. }}$. Por isso, considerava uma função dos escritores e dos intelectuais a produção de literatura para o lumpesinato que se adensava nos anos 50 e 60, com a industrialização e o crescimento das capitais brasileiras: "O operário ama a máquina - enquanto intelectuais caridosos ficam a clamar contra ela e contra a mecanização do homem, sem nunca ter sequer se abeirado do problema."’ . E recomendava aos seus pares: "Portanto, aos poetas, que calem suas lamúrias pessoais ou demagógicas e tratem de construir poemas à altura dos novos tempos, à altura dos objetos industriais racionalmente planejados e produzidos" ". Assim, a paixão do beletrista pelas ditas elevadas produções do espírito, como a poesia lírica, era renegada em nome da sedução do proletário pela máquina, neste caso, a maquinaria literária, com suas engrenagens semânticas, gráficas e sonoras.

3 CAMPOS, Augusto; PIGNATARI, Décio; CAMPOS, Haroldo. Teoria da poesia concreta 2006, p. 215, destaque dos autores.

4 Ibidem, p. 175, grifos do autor.

5 Pode-se notar a disseminação dessa ideia em um contexto heterogêneo de tendências literárias. Este ensaio foi previamente divulgado do prefácio do livro Fluxograma, do poeta baiano Jorge Medauar, lançado em 1959 pelo Clube de Poesia - agremiação de escritores vinculados à estética da Geração de 45. No ano seguinte, foi republicado no suplemento literário Invenção, do Correio Paulistano.

6 Ibidem, p. 175-176.

7 Ibidem, p. 176.

8 Ibidem, p. 176. 
Em que pese essa tentativa de anulação da subjetividade no processo criativo, há de se considerar até que ponto as estratégias de apagamento do eu não dizem, ao contrário, da subjetividade mesma. Dizem das conexões literárias do concretismo com o que estava acontecendo no seu contexto econômico e artístico, do espaço de admiração intelectual pelos seus pares, da construção da unidade discursiva na diferença assumida em cada assinatura, no dizer de Haroldo de Campos, através de um "pluripercurso de ideias e ação em evolução"

Segundo Evelina Hoisel, essas estratégias de anulação de questões pessoais na escrita fazem dos textos concretistas, incontornavelmente, autobiográficos. Para a teórica, a biografia passa a ser entendida não apenas como a narrativa de uma história de vida, pessoal ou de outra pessoa, como o que se costuma denominar "escritas de si" nos estudos literários, trata-se também de uma condição própria da escritura, estabelecida na relação do sujeito com a linguagem e nas diversas estratégias de autorrepresentação do autor através das textualidades em que se insere, como poemas, ensaios, manifestos, depoimentos ou entrevistas.

\footnotetext{
É através do perigoso pacto do sujeito com a linguagem na qual ele imprime os seus rastros, que se erige sua biografia. A lição (auto)biográfica de Paul Valéry data do final do século XIX e é bastante radical e enfática: mesmo uma teoria é autobiográfica. Uma equação matemática é autobiografia. Nessa perspectiva teórica, até os manifestos da poesia concreta são autobiográficos. Neles, encontram-se processos de dramatização desses intelectuais, encenações que apelam para as estratégias coreográficas e persuasivas variadas, no sentido de dar visibilidade às marcas que pretendem perseguir nos seus textos para chegar a um objetivo com rigor matemático e vontade de radicalidade ${ }^{10}$.
}

Como um negativo fotográfico, o esvaziamento da subjetividade na poética do concretismo produz o seu duplo, a subjetividade mesma, por isso, querendo-se antibiográfica, a escritura faz-se biográfica ${ }^{11}$. Nesse sentido, algumas questões de leitura se apresentam quando pareamos estas duas obras ficcionais de Décio Pignatari - O rosto da memória e Panteros - diante das ideias constituintes de seu projeto intelectual, desde o período vinculado à vanguarda. Como se deu a passagem de uma biografia oblíqua, colocada em escanteio pelas encenações de racionalidade na execução do programa concretista, até a produção de narrativas ficcionais com elementos notadamente autobiográficos? Em que contexto se insere esta passagem da poesia à prosa, da

9 Ibidem, p. 10

10 HOISEL, Evelina. “(Auto)Biografias concretistas: desafios”, 2019, p. 172.

11 Termo proposto por Evelina Hoisel em sua tese de doutorado, defendida em 1996 (USP), sobre a obra de João Guimarães Rosa. Cf. HOISEL, 2006, 2019. 
antibiografia para a autobiografia? Estaria Décio Pignatari dando um salto biográfico em sua obra, semelhante ao "salto participante" dado pelo trio concretista, quando convocados pelo entorno literário a se posicionarem sobre as questões políticas e sociais dos anos 60 ? $^{12}$

A partir dos anos 80, os discursos de e sobre memória ganharam força na indústria cultural, no âmbito político, bem como nos temas de pesquisas acadêmicas mundo afora. Esse "boom da memória", no dizer do historiador Jay Winter"13, foi sintomático do modo como as pessoas e, por efeito, as sociedades passaram a produzir e a circular as suas narrativas sobre o passado para construir o futuro. Para Winter, a mudança na ordem política e econômica mundial com o fim da Guerra Fria não foi a única responsável por essa explosão dos discursos de memória de políticos, ativistas, sobreviventes aos fatos marcantes daquele século.

Contribuíram também as demandas de reparação levantadas por grupos sociais historicamente subalternizados pelos crivos de gênero, raça, etnia, nacionalidade e sexualidade, que agora se faziam ver e ouvir de maneira cada vez mais expressiva. A proliferação de tecnologias de comunicação também possibilitou o registro e a disseminação das imagens e vozes de sujeitos, há muito tempo, subrepresentados na mídia, nos materiais escolares ou nos arquivos da história oficial. De acordo com o historiador, o desenvolvimento dos sistemas de educação nos países ocidentais e, por conseguinte, a elevação da taxa de escolaridade média da população também ajudaram

12 Na sinopse do movimento de poesia concreta brasileira, consta sobre o ano de 1961: "D. Pignatari é designado relator da seção 'Poesia' do II Congresso Brasileiro de Crítica e História Literária, FFCL de Assis, SP (julho). Em sua tese-relatório 'Situação Atual da Poesia no Brasil', coloca a questão participante em termos de uma poesia de vanguarda." (CAMPOS, PIGNATARI, CAMPOS, Teoria da poesia concreta: textos críticos e manifestos 1950-1960, 2006, p. 266). O ensaísta Gonzalo Aguilar analisa deste modo o "salto participante": “[...] os critérios modernistas foram tão persistentes que resulta muito mais adequada a figura da virada do que a de 'salto’ para descrever essa mudança, já que os integrantes do grupo não questionaram seus pressupostos, mas sim se preocuparam em integrar, a partir de sua poética, as mudanças do contexto. O ideologema da forma, inicialmente definido de acordo com critérios autônomos (como 'isomorfismo') e ampliado depois como uma forma mentis da sociedade contemporânea, foi considerado, nessa etapa, necessário para dinamizar a articulação entre o processo revolucionário e a poesia." (AGUILAR, Gonzalo. Poesia Concreta Brasileira: As Vanguardas na Encruzilhada Modernista, 2005, p. 93, grifos do autor).

13 WINTER, Jay. “a geração da memória: reflexões sobre o 'boom da memória' nos estudos contemporâneos de história”, 2006. 
a consolidar o mercado consumidor de uma vasta gama de produções culturais, como livros, filmes, programas de televisão, exposições museológicas e espetáculos, sobre o passado de personalidades, países, sítios arqueológicos e grupos étnicos ${ }^{14}$.

Já no âmbito da crítica cultural, Leonor Arfuch identifica alguns pontos-chave para analisar as diversas formas de representação do sujeito na contemporaneidade ${ }^{15}$. Como um construto filosófico, econômico e cultural da modernidade eurocentrada, a noção de indivíduo tracejou os contornos da propriedade privada, do espaço da intimidade e da concepção de cidadania no Estado moderno. Também serviu de parâmetro para o surgimento de formas discursivas como as confissões de natureza ética e filosófica, os diários, as memórias e o romance moderno ${ }^{16}$. Esses gêneros formaram a base do que Arfuch propõe como o "espaço biográfico" contemporâneo, isto é, uma "confluência de múltiplas formas, gêneros e horizontes de expectativas"17 sobre o modo como o sujeito produz a sua identidade e organiza a própria história. Além do feixe de narrativas do eu, o espaço biográfico, para a ensaísta argentina, é também "um clima de época" ${ }^{118}$, marcado tanto pela elisão das fronteiras entre o público e o privado quanto pela ampliação das estratégias de autorrepresentação do sujeito - seja ele um escritor, um ativista, uma celebridade da mídia ou uma pessoa anônima.

O protagonismo das universidades e instituições arquivísticas na custódia e na pesquisa de espólios literários também é acompanhado pelo interesse do público-leitor na edição ou reedição da obra de autores(as) que ficaram nos arquivos da história, como Maria Firmina dos Reis, Carolina Maria de Jesus, Beatriz Nascimento e Lélia Gonzalez. Além disso, pode-se observar a conscientização dos escritores sobre os aspectos materiais do processo criativo, como a escolha do suporte de escrita ou as formas de preservação de versões impressas ou digitais dos seus trabalhos.

14 Além da indústria cultural, um outro mercado, igualmente lucrativo, formou-se em torno da "cultura da terapia" (Ibidem, p. 80) e do autocuidado físico e psicológico, sintetizado pela frase latina já banalizada "mens sana in corpore sano" (mente sã em um corpo são). Nesse filão, poderíamos mencionar as incontáveis publicações de manuais de autoajuda, os programas de televisão sensacionalistas que exploram os dilemas psicológicos da vida ordinária, comum, os canais de vídeo que mesclam coreografias de ritmos como pop, axé, funk, salsa, zumba com promessas de emagrecimento e boa forma até os projetos de relançamento de obras fundamentais da Psicologia, da Psicanálise e da Psiquiatria. Antes de ser uma projeção das características de uma época sobre o autor e as obras, os aspectos mencionados servem de contexto para pensarmos o sistema de valores e expectativas que circundam a produção e da recepção dos discursos sobre o passado, a memória e a subjetividade no tempo presente.

15 ARFUCH, Leonor. O espaço biográfico: dilemas da subjetividade contemporânea, 2010.

16 Ian Watt (2010).

17 ARFUCH, Leonor. O espaço biográfico: dilemas da subjetividade contemporânea, 2010, p. 58.

18 Ibidem, p. 58. 
$\mathrm{Na}$ literatura brasileira contemporânea, como um desdobramento da relação entre literatura, autobiografia e memorialismo, tem se estreitado cada vez mais a relação entre ficção e arquivo. Rompendo o estereótipo de "vestígio" de um processo criativo ou de "ruína" da história, o arquivo tornou-se um elemento integrante da criação literária, ou seja, participa a produção de sentidos da obra tanto quanto o universo ficcional estritamente concebido. Podemos denominar esse fenômeno como uma potência arquivística da literatura contemporânea, que reside em certas práticas observáveis, isoladamente ou conjugadas, em ficções das últimas décadas. Do ponto de vista da materialidade dos livros, pode-se notar a reprodução de fac-símiles de documentos de arquivos (pessoais ou históricos) ou a transcrição datiloscritas de documentos (reais ou imaginários) vinculados ao enredo. Nos paratextos editoriais, como orelhas e textos de apresentação, destacam-se os relatos dos autores sobre as particularidades do seu processo criativo e as suas formas de guardar os seus manuscritos.

A esse aspecto, também confluem as cenas de "arquivamento do eu"19, nas quais uma personagem organiza os seus papéis, descarta documentos, doa acervos e coleções para instituições ou herda arquivos, bem como as cenas nas quais uma personagem está a pesquisar em arquivos públicos. Ainda no tocante à inventiva literária, também é possível notar que essas cenas, por vezes, são recriações do processo autoral de pesquisa, das etapas de redação de uma obra ou das práticas de arquivamento do próprio escritor por meio da autoficçãa ${ }^{20} \mathrm{e}$ da metaficção, embaralhando as referências entre o arquivo pessoal e o arquivo imaginado na criação literária. Por exemplo, destacase na produção de Judith Grossmann a representação ficcional de arquivos pessoais e de práticas de autoarquivamento pelas personagens, que metaforizam estratégias similares às da escritora por meio da autoficção. Igualmente, nos paratextos de seus livros escritos nos anos 90, a autora sinaliza informações sobre os seus arquivos e os seus critérios de organização.

Se a biografia era o ponto de partida para a rasura das fronteiras entre ficção e realidade na literatura contemporânea, desta vez, a representação do arquivo nos textos ficcionais, a materialidade dos livros e as práticas de arquivamento do escritor servem como gatilho para esse tipo de rasura. A literatura e o arquivo tornam-se, deste modo, instâncias através das quais são produzidas diferentes representações do escritor.

19 ARTIÈRES, Philippe. “Arquivar a própria vida”. Revista Estudos Históricos, 1998, p. 9-34.

20 autofição especular: "Baseada em um reflexo do autor ou do livro dentro do livro, essa tendência da fabulação de si não deixa de lembrar a metáfora do espelho. O realismo do texto e sua verossimilhança se tornam, no caso, elemento secundário, e o autor não está mais necessariamente no centro do livro; ele pode ser apenas uma silhueta; o importante é que se coloque em algum canto da obra, que reflete então a sua presença como se fosse um espelho." (COLONNA, Vincent. "Tipologia da autoficção", 2014, p. 53). 
Para Reinaldo Marques, o arquivo pessoal do escritor, constituído pela diversidade de documentos da sua trajetória de vida, ao ganhar o espaço público, torna-se um "arquivo literário" e, por efeito, uma usina de "imagens do escritor" e críticos. Valendo-se da semântica do termo "usina", mobilizada por Gilles Deleuze e Félix Guattari no campo da filosofia, Marques associa a natureza plurissignificativa da linguagem à natureza plurissignificativa dos documentos arquivísticos. Os arquivos e coleções, além de documentarem um processo criativo, também projetam as estratégias de autorrepresentação do titular do arquivo, o escritor, seja no conteúdo dos documentos, seja na maneira pela qual preserva ou descarta os próprios manuscritos ${ }^{22}$.

A partir desse contexto, podemos situar O rosto da memória e Panteros, de Décio Pignatari. Em nossas pesquisas, buscamos analisar a expressão dessa potência arquivística na literatura brasileira contemporânea. O rosto da memória, lançado em 1986, é constituído por doze textos cuja forma não se enquadra em um gênero literário específico. São quase-contos, quase-crônicas, quase-poemas, quase roteiroscinematográficos: frasca, noosfera, jacentes!, pháneron, incipit, pessoinhas, franquisténs 1, franquisténs 2, teleros, o que chopin 1, o que chopin 2, aquelarre, seguidos das notas visuais e da biografia do autor.

Os elementos formais que poderiam ser indicativos de algum gênero literário, como o lírico, o épico ou o dramático, são mobilizados sugestivamente nos doze textos, sem que possamos encaixá-los dentro de uma tipologia específica. A possibilidade de identificação do gênero textual ou da intencionalidade do escritor nestes textos é sempre provisória, diante da abertura a uma infinidade de sentidos produzidos pela

21 MARQUES, Reinaldo. “O arquivo literário e as imagens do escritor”, 2015, p. 87-114.

22 Anotações e papéis pessoais como formas de produção da subjetividade não são exclusivas do contexto literário, tampouco do circuito de produção e recepção da literatura como conhecemos atualmente. Segundo Michel Foucault (A hermeneutica do sujeito, 2010), remonta à Antiguidade e à Idade Média o papel da escrita, da autorreflexão e do cuidado com as anotações pessoais como técnicas do "cuidado de si", espécie de cultivo da própria conduta e do modo de ser valoroso por meio do "conhecimento de si”. Atendo-se a documentos dos séculos XIX e XX, Philippe Artières (1998) propõe que a prática de "arquivamento do eu", pela coleção de toda sorte de documentos pessoais, constitui uma estratégia de produção da própria identidade, tanto por uma "injunção social" que demanda a comprovação de uma identidade civil/pública perante as instituições, quanto por uma "intenção autobiográfica", desejo pelo qual "construímos uma imagem, para nós mesmos e às vezes para os outros" (ARTIÈRES, P. "Arquivar a própria vida”, Revista Estudos Históricos, 1998, p. 10). Já no contexto literário particularmente, Reinaldo Marques (2015) discute de que maneira o "arquivo do escritor", quando deslocado do recinto privado para o espaço público de universidades e centros de pesquisa, torna-se um "arquivo literário" e passa a funcionar como uma "usina de imagens heterogêneas dos escritores” (MARQUES, R. "O arquivo literário e as imagens do escritor", 2015, p. 90), disseminadora das variadas representações emanadas tanto das práticas de "arquivamento do escritor", como seleções, exclusões, recortes e ordenamentos dos seus documentos pessoais e dos seus manuscritos, quanto das relações discursivas estabelecidas entre o conteúdo do arquivo e a vida que se pretende guardada. 
intensidade do trabalho linguístico. O texto introdutório do livro é extraído Confissões, de Santo Agostinho, de cuja citação o título fora escolhido. Com esta citação, não é apenas evocado o filósofo medieval, mas toda uma tradição de textos memorialísticos e autobiográficos da qual esse livro agostiniano fora paradigmático.

outras [imagens] irrompem aos turbilhões e, enquanto se pede e se procura uma outra, saltam para o meio, como que a dizerem: 'não seremos nós?'. Eu então, com a mão do espírito, afasto-as do rosto da memória, até que se desanuvie o que quero e lá do seu esconderijo apareça à vista ${ }^{23}$.

Dentre os doze textos, destacarei "pháneron", composto de flashes, fragmentos, cacos de linguagem sobre a adolescência em uma vila situada na Rua da Estação, em Osasco, cidade do interior de São Paulo. "Pháneron", palavra de étimo grego (phaneros), significa o visível, o manifesto, o que pode ser captado pelos sentidos, permanecendo nos labirintos da memória. Nos seis blocos textuais, em caixa alta, as palavras não estão dispostas conforme as convenções ortográficas; elas constroem o caminho tortuoso do fluxo da memória através da linguagem:

\begin{abstract}
CORREUN UAA FIOC ORR / EUE NTROO UTRAV E NZ ESSAC AIXAD' ÁGUAA TÉO SACOL ANTEJOU LAF RIAO SP ÉSN OL IMOA VOZD ISTANTEP ORT ODOSO SL ADOSD OSQ UADRADOSD EC IMEN / TODASA SV EZESQ UEP ONHOO SP ÉSN OS ILÊNC IOD OC ORREDORE STRONDAVAN OSC OSTADO SO CONTRAPESOD EF ERR OP ENDENTEP ARAF E CHARO PORTÃOZINHOR ECORT ADON OP ORTÃ OE DOO UTROL ADOF IMD ET ÚNELC RESCEN AE SQUINAO CILIN ${ }^{24}$.
\end{abstract}

"Pháneron" torce a linguagem verbal em direção a um grau zero da significação, o que, no entanto, não é de todo alcançado, devido à possibilidade de entendimento da sequência das cenas a partir de uma certa regularidade na distribuição das letras. Não se trata de um texto para ler-ouvir a experiência de um narrador, antes disso, é necessário um trabalho persecutório do sentido através da visão, para, assim, desentranhar do texto a lógica de sua composição. Após a entrada na vila (Fig. 1), a passagem pela lateral do Cine Osasco ocorre com uma espiada do que ocorria no interior das salas de exibição por entre as cortinas de uma das janelas: “[...] CADAV EZQ UEP ASSOP ELOS

23 PIGNATARI, Décio. O rosto da memória, 2014, p. 6.

24 Ibidem, p. 55. Livre transcrição: Correu nua a fio correu entro outra vez nessa caixa d'água até o saco lantejoula fria os pés no limo a voz distante por todos os lados dos quadrados de cimen/todas as vezes que eu ponho os pés no silêncio do corredor e estrondava nos costados o contrapeso de ferro pendente para fechar o portãozinho e cortado no portão e do outro lado fim de túnel crescen a esquina o cilin 


\section{ALÃOI AE SPIARP ORU MAD ASP ORTASD OC INEMAE SCRÍNION OE SCUROE NTREB AMBINELASD ET ÁBUAC ELESTEF RANJAS A MAREL"25.}

Da bomboniere para os fundos da habitação, sugere-se a passagem distante da janela da segunda sala de cinema pelo medo do jovem aos cartazes com o famoso personagem da autora britânica Mary Shelley, Frankstein, levado ao cinema em 1931 pelo diretor James Whale, com a atuação de Boris Karloff, e continuado por A noiva de Frankstein, de 1935, e O filho do Frankstein, de 1938:

UE STAVD IANTED AB ONBONNIÈREC HUPETASD EC HOCOLATEL ICORN UMC HÃOD EP APÉISP RATA V ERMELHOV IOLETAM ARAVILHAE NTRET RIZES D EP URPURINAE FIMB RIASD EC ELOFA / NEMT ENHOC ORAGEMD ER EOLHARM UITOO SC ARTAZESD OF RANQUISTÉMT IVEMIJANEIRAE SEDEV OUA TÉA CASAD ${ }^{26}$.

O texto culmina como uma possível cena de espionagem do banho de uma garota em um chuveiro coletivo, situado ao lado do pomar nos fundos da vila, ponto este para o qual se direcionam as setas no canto superior esquerdo do mapa. A seta tracejada que vem da bomboniere se prosta diante do chuveiro, enquanto uma outra seta desloca-se do chuveiro para o corredor aos fundos da casa de Inês (Fig. 1):

[...] EE SPUMAN OU MBIGOD UASU NH ADASD EV ERDED USASP ONTASD EA MENDOIM E MC ASCAE NCRESPANDOO SP EITINHOSO COR TEI NCHADINHOB UCETAD OP ESSEGOU MAI M PIGEMR OSADAL UZIDIAV APORTIZANDOA POLP AQ UER ODOPIAA FENDAG RAND EE MF UGAS EMC ACHINHOSP ELAP POR / TAMBÉMU MC HEIR OD EE RVA-DOCEE FRUTASB ICADASQ UANDOO LHEIO COLARD SP EGADASM OLHADASE MD IA GON ALN $[\ldots]^{27}$.

25 Ibidem, p. 55. Livre transcrição: “Cada vez que passo pelo salão e a espiar por uma das portas o cinema escrínio o escuro entre bambinelas de tábua celeste franjas amarelas.

26 Ibidem, p. 56. Livre transcrição: "Eu estava diante da bonbonnière chupetas de chocolate licor num chão de papéis prata vermelho violeta maravilha e entre trizes de purpurina e fímbrias de celofane / nem tenho coragem de reolhar muito os cartazes do Franquistém tive mijaneira e sede vou até a casa d". 27 Ibidem, p. 56-57. Livre transcrição: "E espuma no umbigo duas unhadas de verde duas pontas de amendoim em casca encrespando os peitinhos corte inchadinho buceta do pêssego uma impingem rosada luzidia vaporizando a polpa que rodopia a fenda grande em fuga sem cachinhos pela porta também um cheiro de erva-doce frutas bicadas quando olhei o colar das pegadas molhadas em diagonal [...]". 
Após os seis blocos textuais, há o mapa de uma vila na Rua da Estação (Fig. 1), paralela aos trilhos da Estação Ferroviária Sorocabana. As setas tracejadas indicam o percurso dessa voz textual, inominada, enunciada entre fragmentos de linguagem, da porta principal ao interior de uma vila, similar aos conjuntos de casas e pequenos comércios em bairros operários.

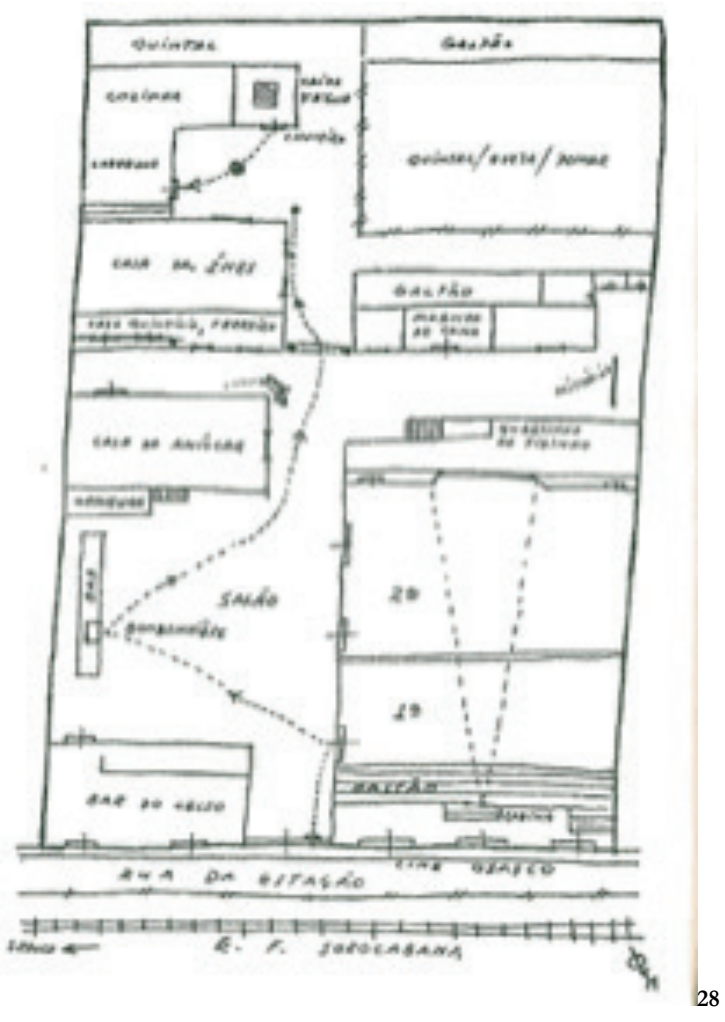

Figura 1

Considerando a atenção dada pelos poetas do concretismo à produção de sentidos da materialidade dos textos, podemos analisar que esse experimentalismo com a frase não se encerra em um mero jogo de palavras. Nesse caso, a poética do Concretismo não deve ser tomada como ponto de explicação para o conjunto da obra dos seus integrantes, que atualizaram e ampliaram muitas das questões defendidas nos manifestos e ensaios reunidos na Teoria da Poesia Concreta. No entanto, é um ponto necessário para compreender a produção literária de cada um dos seus integrantes, principalmente no que há de permanência e de atualização da poética do concretismo na poética de cada escritor. 
O poema concreto, entendido como uma estrutura-conteúdo, não pretendia expressar a lembrança de um momento eternizado ou o estado de ânimo do sujeito, o que era considerado pela Poética como um traço estilístico do gênero lírico ${ }^{29}$. Em vez disso, era colocada em evidência a interação dos elementos semânticos, visuais e fonéticos das palavras em busca do isomorfismo, ou seja, a equivalência entre a forma e o conteúdo do texto literário. Para a poética do concretismo, o como se diz produz sentidos tanto quanto o que se diz. Dessas questões, devém a noção de concretude do poema, demarcada por Augusto de Campos no ensaio poesia concreta, lançado três anos antes do plano-piloto, na revista Fórum, do Centro Acadêmico 22 de Agosto da Faculdade Paulista de Direito (atualmente vinculada à PUC-SP): "Concreta no sentido em que, postas de lado as pretensões figurativas da expressão (o que não quer dizer: posto à margem o significado), as palavras nessa poesia são objetos autônomos" ${ }^{\prime 30}$.

A narrativa "pháneron" resgata esse princípio de isomorfismo, pois um texto cujo conteúdo opera no limite entre a ficção e a autobiografia haveria de ter uma forma que também o fizesse. Se, por um lado, a leitura tortuosa do significante remete a esta mesma tortuosidade do trabalho da memória, por outro, a inserção das fotografias pessoais reforça a natureza ficcional da organização deste material da memória em discurso. Pelo princípio de isomorfismo (forma = conteúdo), a natureza cifrada da linguagem do texto põe em cena esta mesma natureza do aparelho psíquico. Tanto para Freud $^{31}$ quanto para Lacan ${ }^{32}$, o inconsciente organiza-se por meio de uma linguagem intrincada e registra com maior ou menor intensidade as inscrições da memória no aparelho psíquico ${ }^{33}$. A memória, operando nos interstícios entre a consciência e o inconsciente, depara-se, por um lado, com a impossibilidade de tudo guardar, por outro, com o desvão entre a linguagem verbal e esses traços mnêmicos. A aderência

29 STAIGER, Emil. Conceitos fundamentais de poética, 1977.

30 Ibidem, p. 55.

31 FREUD, Sigmund. “Uma nota sobre o ‘bloco mágico’ (1925[1924])”, 1996, p. 251-259.

32 LACAN, Jacques. O Seminário: livro 3, 1988.

33 Freud, em “Uma nota sobre o ‘bloco mágico’ (1925[1924])”, estabelece uma analogia entre o trabalho da memória no aparelho psíquico e o brinquedo infantil conhecido como bloco mágico, uma lâmina sobre a qual se fazem registros. Depois de apagada, os traços mais intensos permanecem inscritos no fundo da lâmina, num acúmulo cifrado de inscrições. Para Lacan, em Seminário: Livro 3 As psicoses, o inconsciente organiza-se como um "tecido de linguagem". Apoiado no repertório da linguística, dá ênfase à palavra, em especial ao significante das palavras (representação), na estruturação do inconsciente, concebido como um tramado de significantes capazes de produzirem o significado 
da linguagem verbal à memória nunca acontece em plenitude; quando se tenta traduzir em palavras o que foi visto, vivido ou ouvido, sempre se volta deste material do inconsciente com uma das mãos vazias ${ }^{34}$.

Essa estrutura sintática cifrada relaciona-se com o que discutia Marshal McLuhan, em A Galáxia de Gutenberg. O surgimento da imprensa teria ocasionado uma revolução não apenas nas formas de produção e circulação dos livros, mas também no âmbito linguístico, cognitivo. McLuhan concede à imprensa o status de catalisador de uma forma de cognição pautada na valorização da linguagem verbal e da lógica em detrimento de outros sistemas de signos. Para ele, a alfabetização fonética traria um débito na competência linguística do sujeito, que é condicionado a transformar o que lê em uma voz, a buscar o conteúdo de uma mensagem em forma de frase ${ }^{35}$.

Por outros caminhos, Jacques Derrida, em A estrutura, o signo e o jogo no discurso das ciências humanas, assinala de que maneira o pensamento ocidental é arregimentado tanto pelo "fonocentrismo", que pressupõe a escrita como uma representação da voz e do discurso racional de um sujeito, quanto pelo "logocentrismo", o estabelecimento de relações associativas de causalidade e contiguidade na percepção da realidade. $\mathrm{Na}$ contramão disso, o texto pignatariano não dá a ouvir meramente a voz discursiva de um narrador, a contar a sua experiência passada, porque a leitura demanda uma experiência sensorial do significante, através da visualidade dos labirintos da memória.

Nesse trabalho criativo com a forma linguística dos blocos textuais de "pháneron", é possível observar a migração de questões teóricas que constituem

34 Lição que já nos é dada pela personagem GH, de Clarice Lispector,: "A realidade é a matéria-prima, a linguagem é o modo como vou buscá-la - e como não acho. Mas é do buscar e não achar que nasce o que eu não conhecia, e que instantaneamente reconheço. A linguagem é o meu esforço humano. Por destino tenho que ir buscar e por destino volto com as mãos vazias." (LISPECTOR, Clarice. A Paixão Segundo G.H: romance, 2009, p. 176).

35; O teórico da informação Marshal McLuhan, em A galáxia de Gutenberg: a formação do homem tipográfico, atribui ao alfabeto fonético a primazia do "conteúdo" sobre a "forma" e considera o surgimento da tipografia o ponto de virada para o homem ocidental. 
o projeto intelectual do "escritor múltiplo"36 que foi Décio Pignatari. Como um importante disseminador da Semiótica de Charles Sanders Peirce ${ }^{37}$ no contexto brasileiro e internacional, Pignatari foi professor e pesquisador desse campo, tendo participado da fundação da Associação Internacional de Semiótica. No ensaio "A ilusão da contiguidade", publicado no livro semiótica \& literatura, Pignatari discute de que maneira o alfabeto fonético e a morfossintaxe das línguas ocidentais induzem a percepção da realidade através de relações lógicas de contiguidade (associação por proximidade) e causalidade (causa-efeito):

O chamado "Logocentrismo" seria uma outra denominação para a associação por contigüidade. Quando a palavra é tomada como código central, somos levados a crer que todos os signos só adquirem 'sentido' quando traduzidos em "palavrês", em código verbal. A mente racional, conseqüentemente, é aquela que opera por contigüidade ${ }^{38}$.

Por essas relações de contiguidade e causalidade, tenderíamos a interpretar as fotografias pessoais (Fig. 2) que aparecem após o mapa da Rua da Estação como uma prova da verdade dos fatos por detrás do discurso cifrado do autor. Na primeira delas, há uma jovem não nomeada, apenas designada pelo pronome de terceira pessoa "Ela", e nas três outras Décio Pignatari quando criança, jovem adulto e um pouco mais velho: "Ela, pivô do Pháneron/1938; Ele, quando viveu o Pháneron; Ele, quando registrou o Pháneron/1954; Ele, quando desrefez o Pháneron, 1973”39. Dada a aparição do autor em três destas fotografias, como a emprestar o corpo para uma de suas personagens, "pháneron" produz essa ilusão da contiguidade a que se referia Décio Pignatari, traduzida no seguinte raciocínio: se o autor aparece nas fotografias, então toda a

\footnotetext{
36 O projeto de pesquisa “O escritor e seus múltiplos: migrações” (UFBA) denomina por esse termo o perfil de autor que conjuga a criação literária com a atividade acadêmica em instituição de ensino superior e a produção teórico-crítica. Segundo Flora Süssekind (2002), houve, nos anos 60, o deslocamento da "crítica de rodapé" em jornais, revistas e suplementos literários para o contexto universitário, na figura do "crítico-scholar", a partir da expansão dos cursos de pós-graduação nas universidades brasileiras. Segundo Evelina Hoisel (HOISEL, E. Teoria, crítica e criação literária: o escritor e seus múltiplo, 2019), o surgimento do "escritor múltiplo" da contemporaneidade, além de se relacionar com essa expansão universitária, também se vincula à figura do "poeta-crítico" da modernidade, como Charles Baudelaire, Edgar Allan Poe, Paul Valéry e T. S, Eliot, e à criação de disciplinas propedêuticas no currículo dos cursos de Letras, tais quais a Teoria da Literatura, a Teoria da Informação e a Semiótica, em cujas linhas de pesquisa e docência pôde-se notar a atuação de escritores com formação acadêmica nessas áreas.

37 PEIRCE, Charles Sanders. Semiótica, 2012.

38 PIGNATARI, Décio. semiótica \& literatura, 2004b, p. 167.

39 Idem. O rosto da memória, 2014, p. 59.
} 
narrativa é verdadeira e trata da sua vida. No entanto, as fotografias do arquivo pessoal na materialidade do livro põem em crise a tentativa de projeção da história de vida do autor sobre o texto literário.

Já no ensaio "O ícone e o ocidente", integrante do mesmo livro mencionado, o autor discute o poder subversivo da arte, como um "signo icônico" (de experiência direta com a realidade), diante das convenções e dos conceitos socialmente estabelecidos - "signos simbólicos", que não possuem uma relação direta com os fenômenos a que se referem. Nesses baixios da linguagem, está o experimentalismo realizado em suas obras ficcionais. O carnaval, como signo da contestação às estruturas de poder da Idade Média cristã, serve como metáfora do trabalho do escritor com a forma literária nestes dois aspectos, tanto a estrutura cifrada da sintaxe do texto quanto o hibridismo de linguagens por meio da relação entre as palavras e as imagens:

\footnotetext{
A arte, ou melhor, o ícone, é aquele riso rabelaisiano da praça pública que desierarquiza todas as formas, atraindo-as para os baixos corporais da linguagem. [...] Irrompendo pelo discurso, o ícone rompe o automatismo verbal - que nos conduz à ilusão de que as coisas só têm 'significado' quando traduzidas sob a forma logológica - resgatando, regenerando e desvelando o maravilhoso mundo das palavras ${ }^{40}$.
}

O riso rabelaisiano, provindo dos estratos mais populares da sociedade medieval, inconforme aos ditames da ascese e do comedimento, a despeito de todas as tecnologias de controle social desse período, é o mesmo riso estampado pelo autor, quando criança, na primeira das três fotografias em que aparece (Fig. 2). A rasura das fronteiras entre a linguagem verbal e a linguagem não verbal reverbera a rasura das fronteiras entre a ficção e a autobiografia, em outras palavras, o hibridismo da forma está atrelado ao hibridismo do conteúdo.

$\mathrm{Na}$ teoria literária, Philippe Lejeune ${ }^{41}$ considera que as ficções com esses traços autobiográficos estabelecem um "pacto fantasmático" de leitura, situado entre o "pacto referencial" da autobiografia, com suas promessas de verdade sobre os fatos relatados para o leitor, que nela busca a expressão fidedigna de um sujeito, do outro, o "pacto romanesco", a partir do qual um escritor é livre para criar uma realidade literária distinta da realidade empírica.

40 PIGNATARI, Décio. semiótica \& literatura, 2004b, p. 190-191.

41 LEJEUNE, Philippe. O pacto autobiográfico: De Rousseau à Internet, 2014. 

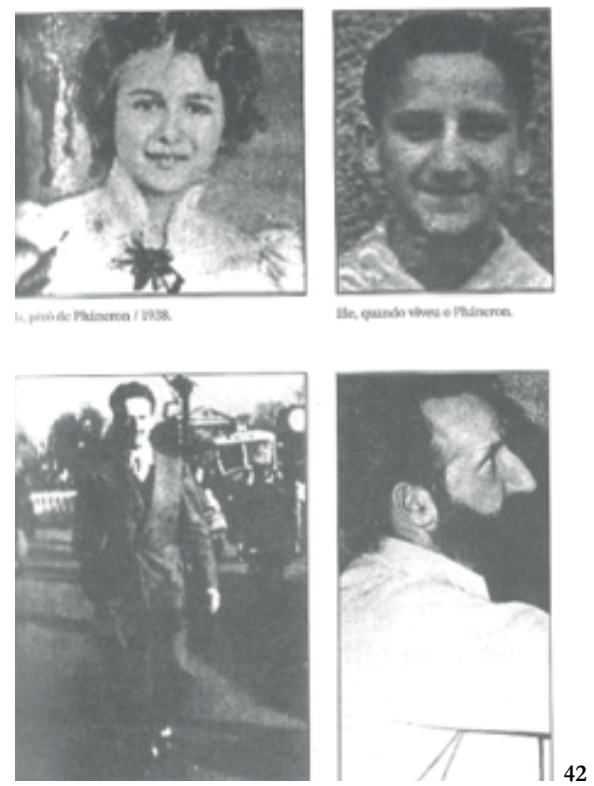

Figura 2

Na fenda entre esses dois polos, situa-se o "pacto fantasmático" da autoficção, identificado pelo crítico francês como uma "forma indireta de pacto autobiográfico" em obras literárias com elevada sugestividade de questões pessoais dos seus autores: "O leitor é assim convidado a ler os romances não apenas como fiç̧ões remetendo a uma verdadeira 'natureza humana', mas também como fantasmas reveladores de um indivíduo" "44. Embora o emprego da palavra "reveladores", no seu contexto semântico, pressuponha o texto como revelação da verdade de uma vida por detrás do texto, a literatura de natureza autoficcional, produzida a partir da década de 1970, deslocou o estatuto do sujeito como ponto de coerência para a interpretação do texto literário.

Em O rosto da memória, outro texto que acentua as diversas estratégias de autorrepresentação do escritor é a "biografia", escrita em terceira pessoa por Décio Pignatari e apresentada ao final do livro. É iniciada por uma fotografia pessoal (Fig. 3), com a boca semiaberta, como no meio de uma fala, o que projeta uma representação do intelectual como aquele que fala para uma sociedade, aquele que dispõe de um discurso e de um sistema de ideias. Diferentemente do memorial, gênero em que o sujeito revisita momentos representativos de sua trajetória acadêmica, a biografia em terceira pessoa insinua um distanciamento entre o redator e os fatos apresentados. 


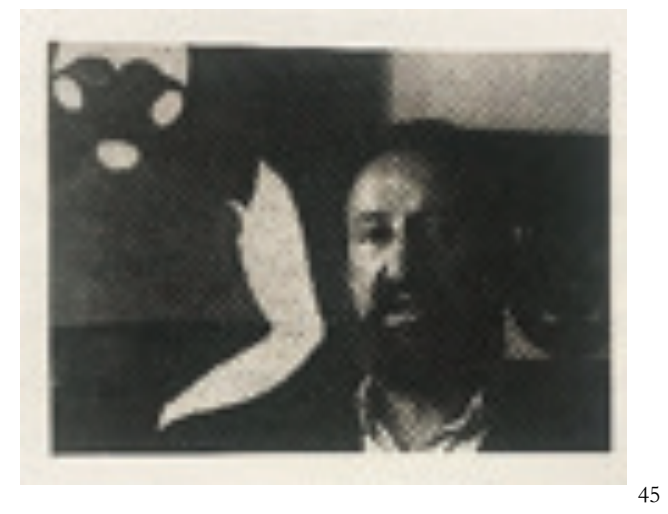

Figura 3

Sem cair na pernóstica armadilha de escrever o seu próprio nome em terceira pessoa, Décio Pignatari constrói essa biografia através do emprego de recursos linguísticos de uma suposta neutralidade, como o sujeito oculto, "Depois de nascer em Jundiaí e viver 25 anos em Osasco (SP), quatorze dos quais viajando diariamente pelos trens de subúrbio da Estrada de Ferro Sorocabana, decidiu mandar-se para outras partes, europeias, não sem antes despedir-se de Oswald [..]"46, e pronome oblíquo, “[...] Roman Jakobson o convidou para ser também co-fundador da Associação Internacional de Semiótica, em Paris." ${ }^{47}$.

Este suposto distanciamento do sujeito perante a linguagem encena o mesmo ideal de apagamento da subjetividade almejado pela poesia concreta nas décadas anteriores, contra o risco de incorrer no crime de lesa-majestade aos ideais concretistas que representaria a enunciação em $1^{\mathrm{a}}$ pessoa. No entanto, somente é possível alcançar esse grau máximo de objetividade através do grau máximo de proximidade de quem conhece a própria vida: "Acha que talvez tenha feito meia revolução na poesia, almeja fazer mais meia: na prosa. No país da Geleia Geral, quem já conseguiu fazer uma inteira?" ${ }^{48}$. A criteriosa eliminação das marcas linguísticas de subjetividade indica a natureza performática dos textos de Décio Pignatari, pois esse insidioso pacto de neutralidade com a linguagem é mais uma das formas pelas quais o escritor aciona questões teóricas e autobiográficas presentes em sua obra, seja pelo viés da autoficção e dos documentos arquivísticos reproduzidos em seus livros, seja pela encenação da racionalidade com a linguagem. 
Essas questões também estão presentes em Panteros, publicado seis anos depois de $O$ rosto da memória, no ano de 1992. A paginação diferenciada do volume parece conduzir o leitor não ao final, às últimas folhas, mas ao âmago do livro, a um certo ponto nodal, ao coração do livro. Na primeira metade, estão os capítulos ímpares, na segunda metade, os pares; os capítulos ímpares devem ser lidos na ordem convencional (da página esquerda à direita), já os capítulos pares, da direita para esquerda (do "fim" ao meio). A obra retoma a temática amorosa com o tom de picardia e os rasgos da narrativa que nos reporta às Memórias Sentimentais de João Miramar, do modernista Oswald de Andrade. A paixão é vivenciada em três níveis pelo personagem Miro, sobre o qual repousa o foco, a "mirada" narrativa. A paixão carnal pela garota, a paixão literária pelos escritores que nutrem os seus poemas e as suas cartas de amor, e a paixão desportiva pelo time ferroviário osasquense de futebol ("SOMA").

As duas primeiras paixões estão entrelaçadas, uma alimenta a outra. No jogo de espera das missivas trocadas, de um lado, tem-se Miro, declaradamente um redator, um jovem escritor que busca entender esse sentimento através da leitura de autores clássicos da temática amorosa, como Shakespeare, Machado de Assis, Castro Alves e Olavo Bilac: "Na língua da minha caneta, o boato da beleza se transforma em fato poético. Apascento ventos, arrasto o coração pela Terra, transmogrifo a vida." ${ }^{49}$. Do outro lado, tem-se o Yara, em cujas cartas destila uma sensualidade felina/ferina a cada missiva correspondida:

\footnotetext{
Cada vez que você escreve, Miro, a panfera percebe que você chega e se achega mais e mais: cada rabisco a lápis, cada vírgula a tinta, cada letra a máquina é um hálito perfumado que se evola de sua goela, é um bofe cheiroso de suas entranhas, é um cheiro lascivo dos poros e dobras ${ }^{50}$.
}

$\mathrm{Na}$ composição do livro, um outro texto aparece subjacente. Não é um dos predecessores mencionados explicitamente, mas uma espécie de repertório implícito que serve de modelo para a narração dos encontros e desencontros de Miro e Yara. Trata-se do conto Uma paixão no deserto, do autor francês Honoré de Balzac. Nele, um jovem soldado provençal, enviado a uma expedição militar no Egito, fora tomado como prisioneiro de guerra pelos árabes. Após fugir, passa a vagar no extenso deserto, sonhando com o retorno à terra natal. Encontra uma gruta, aparentemente aprazível diante das condições climáticas adversas e lá passa os dias enquanto planeja a sua jornada. Certa noite, assustadoramente vem repousar neste mesmo lugar uma pantera,

49 Idem. Panteros, 1992, p. 91.

50 Ibidem, p. 91. 
esplendorosamente ferina, famélica e sensual aos olhos do soldado. Inicialmente, o homem de guerra conjectura todas as possibilidades de matá-la, mas, com o passar dias, o soldado e a pantera acabam travando uma relação amistosa, entre afagos, carícias e ronronares. Certa feita, por um rompante similar àqueles que estão submetidas as paixões mais desmedidas, a fera se volta contra o soldado e lhe morde a perna. Em resposta, o soldado enterra o punhal no pescoço, gesto do qual se arrependeria até o fim do seu suplício no deserto.

Um determinado segmento conto, vertido ao português, é reiteradamente trazido à cena do texto de Panteros, mas sempre em diferença. Nas primeiras páginas, o trecho aparece na íntegra (Fig. 4) e, nas aparições seguintes, com um certo traço de diferença; ora é o enquadramento, semelhante ao zoom in de uma filmagem, ora é um jogo verbo-visual entre as palavras "perfume", "parfemme" (Fig. 5) e o desenho de duas panteras nas letras "mme" (Fig. 6). O conto balzaquiano é associado à paixão entre Miro e Yara, a pantera desejada no(a) te(n)são entre o amor carnal e o amor sublime. Os afagos da pantera e do soldado servem de imagem para as cenas sensuais construídas ora pela memória ora pela imaginação de Miro.

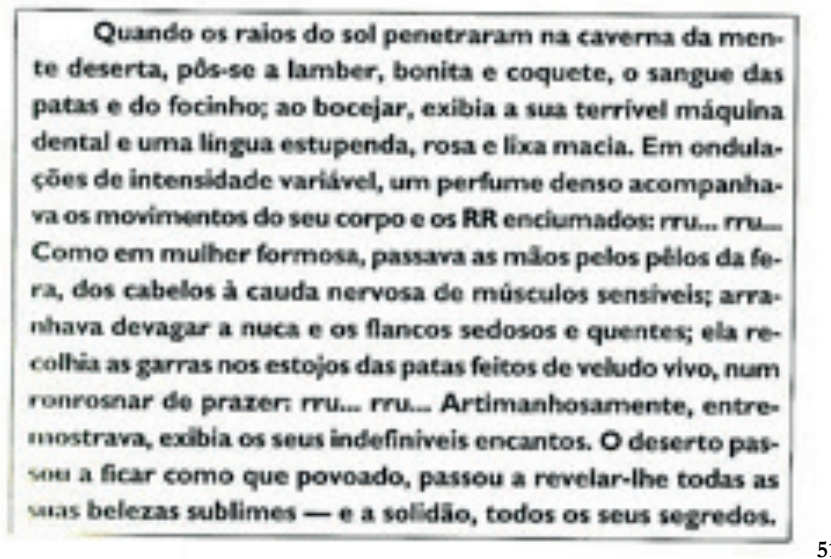

Figura 4

\section{l, rosa e lixa $\mathrm{m}$ n parfemme d e os RR enciu}

Figura 5

51 Ibidem, p. 15.

52 Ibidem, p. 85 (p. 111 conforme a ABNT). 


\section{, rosa e uxa $\mathbf{n}$ \\ parformme \\ e os RR enciu}

Figura 6

Do ponto de vista material, essa colocação de um segundo texto por trás da superfície da página em branco, entre as frestas do papel, já havia sido um procedimento praticado por Décio Pignatari no poema somos como (Fig. 7), publicado em 1975 na revista código, n. 2, editada pelos poetas baianos Erthos Albino de Souza e Antonio Risério. O leitor é estimulado a alcançar a informação escondida em uma outra margem da linguagem. Entre o plano em que se situa o leitor e o plano preto das infinitas e misteriosas possibilidades, há uma fronteira vazada, representada pela cor preta da página, de onde os "signos espiam", instalando um jogo erótico do texto de esconder e exibir a mensagem ${ }^{54}$, como o fizeram o soldado e a pantera do conto de Balzac quanto às suas intenções.

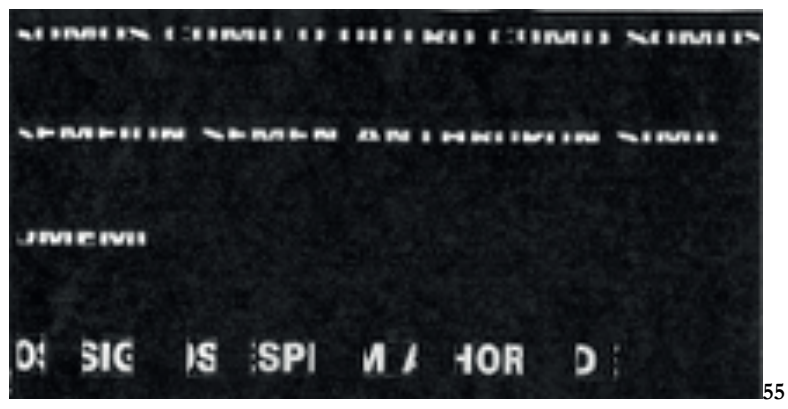

Figura 7 - somos como (1975)

Com o avanço da narrativa, a fisionomia de Yara vai se tornando mais nítida a Miro, de uma distante silhueta feminina pontilhada (Fig. 8) até o nítido busto da jovem (Fig. 11). Esse passo-a-passo da visibilidade da imagem relaciona-se com o trabalho da memória em nosso aparelho psíquico, de uma zona de dispersão que é a inconsciência até o nível da consciência.

53 Ibidem, p. 121 (p. 92 conforme a ABNT).

54 BARTHES, Roland, O prazer do texto, 2010.

55 PIGNATARI, Décio. Poesia, pois époesia, 2004c, p. 205-206. 


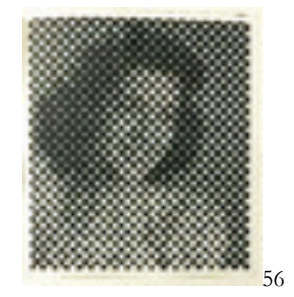

Figura 8 - Yara

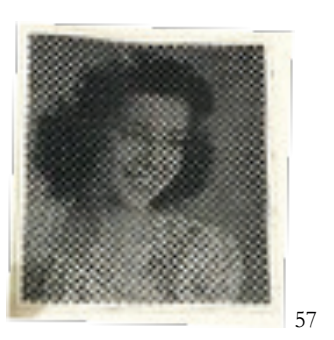

Figura 9

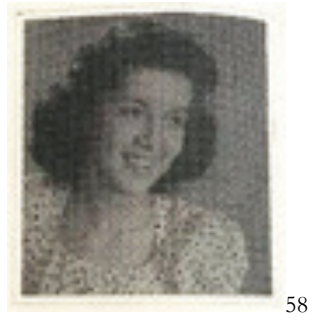

Figura 10

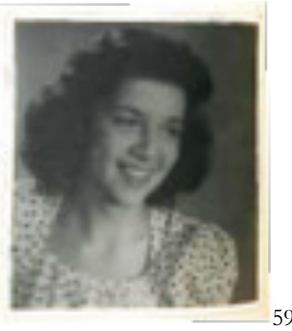

Figura 11

Em sequência, existe a terceira paixão, a desportiva. Miro integra o time de futebol SOMA. Nas fotografias associadas ao time, figura um jovem pouco mais alto do que os demais, de rosto alongado, nariz e queixo pignatarianamente salientes.

56 Ibidem, p. 17.

57 Ibidem, p. 45 (p. 133 conforme ABNT).

58 Ibidem, p. 65 (p. 124 conforme ABNT).

59 Ibidem, p. 123 (p. 90 conforme ABNT). 


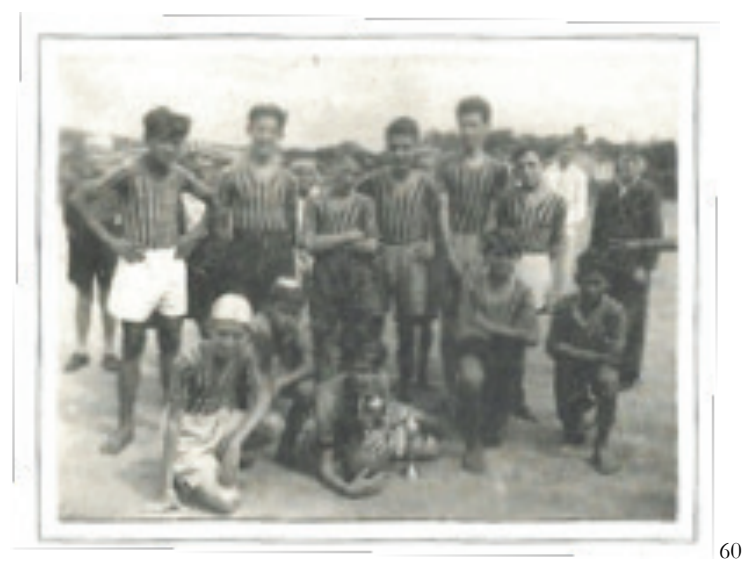

Figura 12 - O time SOMA em idade juvenil. Décio Pignatari é o $2^{\circ}$ da esquerda para a direita (em pé)

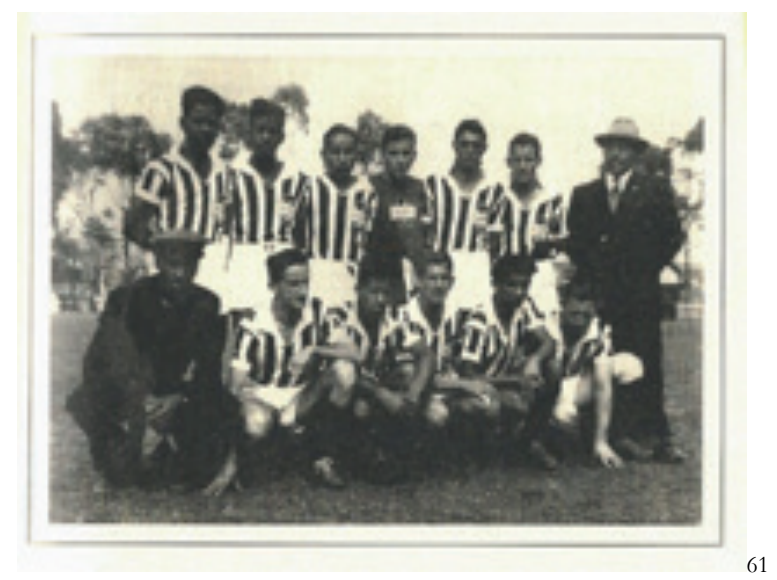

Figura 13 - Décio Pignatari é o $2^{\circ}$ da esquerda para a direita (baixo)

Panteros, "Pan" e "eros", conjugação de duas divindades vinculadas ao desejo e ao amor, também eros em todas as coisas, na imaginação, em uma fotografia do arquivo pessoal. Do ponto de vista temático, os alvos do desejo de Miro são Yara (paixão amorosa), os escritores lidos (paixão literária) e o time de futebol (paixão desportiva). No processo criativo do autor, eros também se encontra na seleção das fotos que viriam a compor os dois livros de ficção, como um investimento na preservação dos documentos arquivísticos, conciliada com a visibilidade conferida pela literatura a essas fotografias.

Por efeito, é também um investimento do desejo do eu em si mesmo, porque, neste caso, a libido de objeto, devotada aos livros e às fotografias, está atrelada à libido do eu. ${ }^{62}$ A seleção das fotografias conjuga tanto a libido do eu quanto a libido do

60 Ibidem, p. 19 (p. 150 conforme ABNT).

61 Ibidem, p. 73 (p. 31 conforme ABNT).

62 A teoria das pulsões (instintos) é proposta por FREUD, Sigmund. "O Ego e o Id (1923)", 1996, p. $15-80$. 
objeto, pois, em última instância, as escolhidas para a composição dos livros, investidas do desejo de preservação, são imagens do próprio Décio Pignatari. Esse grau máximo de espelhamento entre o eu e o objeto, o autor e a sua criação (a obra, o livro), pode ser lido nestes versos de "Eupoema", publicado por Pignatari na revista noigandres, $\mathrm{n}$. 1, em 1952: "Eu não sou quem escreve,/mas sim o que escrevo/Algures Alguém/são ecos do enlevo" ${ }^{63}$.

Dentre os procedimentos da potência arquivística da literatura contemporânea, mencionados no início deste texto, Décio Pignatari põe em prática a reprodução de documentos de seu arquivo pessoal nestes livros, o que potencializa a natureza autoficcional de seus textos devido à figuração do escritor nas imagens associadas às narrativas. Isso corresponde a uma atualização do isomorfismo pretendido pelo concretismo, segundo o qual a forma de uma obra literária deveria equivaler ao conteúdo. No campo da bibliografia dos textos, Donald McKenzie analisa o "status simbólico" ${ }^{64}$ da materialidade de um livro, dada a inseparável conjunção entre a forma e o conteúdo. Por exemplo, o surgimento do romance moderno como gênero literário de expressão da experiência burguesa a partir do século XVII não seria possível sem o surgimento da imprensa tipográfica e a comercialização do livro em brochura como o conhecemos para esse mesmo público burguês. A forma como expressão de uma época e de um conteúdo.

Por essa razão, a materialidade de $O$ rosto da memória e Panteros adquire um potencial significativo. As fotografias pessoais, o mapa desenhado do bairro da adolescência, assim como os recortes de jornais e as reproduções de telas de arte presentes em outras páginas, constituem a rede de documentos arquivísticos pelas quais Décio Pignatari delineia o rosto da memória nas frestas entre a palavra e a imagem, a ficção e a autobiografia, a literatura e o arquivo. O filósofo Jacques Rancière analisa essa relação não causal e não representativa entre os códigos a partir do conceito de "frase-imagem", uma construção intersemiótica sem mais-valia de uma linguagem sobre a outra:

\footnotetext{
A frase-imagem subverte essa lógica. A função-frase ainda é a de encadeamento. Mas, a partir daí, a frase encadeia somente enquanto ela é aquilo que dá carne. E essa carne ou essa consistência, de modo paradoxal, é a da grande passividade das coisas sem razão. A imagem tornou-se a potência ativa e disruptiva do salto, da transformação de regime entre duas ordens sensoriais. A frase-imagem é a união dessas duas funções. É a unidade que desdobra a força caótica da grande parataxe em potência frástica de continuidade e potência imagedora de ruptura. Como frase, acolhe a
}

63 PIGNATARI, Décio. Poesia, pois époesia, 2004c, p. 53.

64 McKENZIE, Donald Francis. Bibliografia e Sociologia dos textos, 2018, p. 23. 
potência paratáxica rejeitando a explosão esquizofrênica. Como imagem, rejeita com sua força disruptiva o grande sono da repetição indiferente ou a grande embriaguez comunal dos corpos ${ }^{65}$.

A frase-imagem situa-se no ponto de tensão entre o fechamento da representação em torno do sentido do discurso verbal e o caráter plurissignificativo das imagens. Esta é a mesma tensão em que reside a ficção de Décio Pignatari, no limiar entre a "potência frástica" e a "potência imagedora" das quais trata Rancière. A pura "potência frástica" estabelece a mais-valia da linguagem verbal sobre as demais e pressupõe a verdade e a coerência do discurso do sujeito sobre si mesmo, por outro lado, a pura "potência imagética" abriria a significação a um nível extremo de sugestividade em que não haveria qualquer referencial de sentido, apenas visualidade.

Entre elas, a conjunção frase-imagem se faz da contaminação de uma potência pela outra, espécie de dupla voltagem da linguagem. A potência imagedora na ficção de Décio Pignatari reside na inserção de fotografias pessoais do escritor à materialidade dos dois livros, na quebra das convenções ortográficas em função de uma sintaxe visual (do olhar) e na paginação diferenciada de Panteros, que desautomatiza a linearidade da leitura de um livro sem começo-meio-fim. Já a potência frástica das imagens nessas duas obras produz o pacto ambíguo de leitura a que se propõem as autoficções no horizonte da literatura contemporânea. ${ }^{66}$

Se, na poesia concreta, era silenciada a "voz" do "sujeito lírico" em nome da visualidade do texto, nas décadas seguintes, $O$ rosto da memória e Panteros sinalizam a dispersão do sujeito na linguagem, ou melhor, nas linguagens, pois a ficção de Décio Pignatari "transmogrifa" a vida e o arquivo como matéria-prima do trabalho ficcional com a palavra e a imagem. Nas fotografias selecionadas, o a(u)tor ${ }^{67}$ empresta o seu corpo aos personagens, tornando-se ele mesmo um signo do texto literário. Contudo,

65 RANCIÈRE, Jacques. O destino das imagens, 2012, p. 56-57.

66 autofição especular: "Baseada em um reflexo do autor ou do livro dentro do livro, essa tendência da fabulação de si não deixa de lembrar a metáfora do espelho. O realismo do texto e sua verossimilhança se tornam, no caso, elemento secundário, e o autor não está mais necessariamente no centro do livro; ele pode ser apenas uma silhueta; o importante é que se coloque em algum canto da obra, que reflete então a sua presença como se fosse um espelho." (COLONNA, “Tipologia da autoficção”, 2014, p. 53). 67 Termo usado pelo também escritor múltiplo Evando Nascimento, em "retrato desnatural (diários 2004-2007)", na epígrafe da primeira seção "escrevendo no escuro": "pois se tornou/imperativamente necessário/ escrever na primeira pessoa, mas/sem ingenuidades, com todos os disfarces/o a(u)tor" (NASCIMENTO, 2008, p. 11). Segundo Hoisel (2019), "A grafia da palavra a(u)tor é elucidativa, pois não se refere apenas a uma simultaneidade de máscaras, mas explicita como uma persona já se encontra na outra, uma máscara agrega-se à outra, compondo uma grande mascarada" (HOISEL, Teoria, crítica e criação literária: o escritor e seus múltiplos, 2019, p. 45). 
essa camada de significado das fotografias é acionada apenas por aqueles que o reconheçam, comprovando-se que o sentido de um documento de arquivo reside nos usos que se fazem deste.

Junto com esse material narrativo, os ensaios e a biografia em terceira pessoa também constroem a cenografia das diversas poses assumidas pelo escritor em sua obra, como o adolescente fescenino, o jovem leitor, o jogador de futebol, o poeta concretista, o professor de Semiótica ou o arquivista de si mesmo, selecionando os documentos que viriam a integrar O rosto da memória e Panteros. Dado o salto biográfico na virada dos anos 80, o resto é saber se o Décio ficcionista já estava dentro do Décio poeta-designer de linguagens, mas se te lembras bem do Décio menino, hás de saber que um estava dentro do outro, como a fruta dentro da casca.

\section{Referências Bibliográficas}

AGUILAR, Gonzalo. Poesia Concreta Brasileira: As Vanguardas na Encruzilhada Modernista. São Paulo: Editora da Universidade de São Paulo, 2005.

ARFUCH, Leonor. O espaço biográfico: dilemas da subjetividade contemporânea. Tradução de Paloma Vidal. Rio de Janeiro: EdUERJ, 2010.

ARTIÈRES, Philippe. Arquivar a própria vida. Revista Estudos Históricos: Arquivos Pessoais [online]. Rio de Janeiro, v. 11, n. 21, p. 9-34, 1998.

BALZAC, Honoré de. Uma paixão no deserto. Disponível em http:/ /www. tyrannusmelancholicus.com.br/cronicas/9032/uma-paixao-no-deserto. Acesso em: abr. 2020 .

BARTHES, Roland. O Praz̧er do Texto. 5. ed. Tradução de J. Guinsburg. São Paulo: Perspectiva, 2010.

BOSI, Alfredo. História concisa da literatura brasileira. 43. ed. São Paulo: Cultrix, 2006.

CAMPOS, Augusto de; PIGNATARI, Décio; CAMPOS, Haroldo de. Teoria da poesia concreta: textos críticos e manifestos 1950-1960. 5. ed. Cotia, SP: Ateliê Editorial, 2006.

COLONNA, Vincent. "Tipologia da autoficção”. In: NORONHA, Jovita Maria Gerheim. Ensaios sobre autofiç̧ão. Belo Horizonte: Editora UFMG, 2014, p. 39-66. 
DERRIDA, Jacques. A estrutura, o signo e o jogo no discurso das Ciências Humanas. In: DERRIDA, Jacques. A escritura e a diferença. 2. ed. Tradução de Maria Beatriz Marques Nizza da Silva. São Paulo: Perspectiva, 1995. p. 229-249.

FOUCAULT, Michel. A bermenêutica do sujeito: curso dado no Collège de France (1981-1982). Tradução de Márcio Alves da Fonseca, Salma Tannus Muchail. 2. ed. São Paulo: Martins Fontes, 2010.

FREUD, Sigmund. "O Ego e o Id (1923)". In: FREUD, Sigmund. O Ego e o Id e outros trabalhos (1923-1925). Tradução de Eudoro Augusto Macieira de Souza sob a direção geral de Jayme Salomão. Rio de Janeiro: Imago, 1996. p. 15-80.

FREUD, Sigmund. “Uma nota sobre o ‘bloco mágico' (1925 [1924])”. In: FREUD, Sigmund. O Ego e o Id e outros trabalhos (1923-1925). Tradução de Eudoro Augusto Macieira de Souza sob a direção geral de Jayme Salomão. Rio de Janeiro: Imago, 1996. p. 251-259.

HOISEL, Evelina. Grande sertão: veredas - uma escritura biográfica. Salvador: Assembleia Legislativa do Estado da Bahia; Academia de Letras da Bahia, 2006.

HOISEL, Evelina. Teoria, crítica e criação literária: o escritor e seus múltiplos. Rio de Janeiro: Civilização Brasileira, 2019.

LACAN, Jacques. O Seminário: livro 3 As psicoses. 2. ed. Versão brasileira de Aluísio Menezes. Rio de Janeiro: Zahar, 1988.

LEJEUNE, Philippe. O pacto autobiográfico: De Rousseau à Internet. 2. ed. Organização e tradição Jovita Maria Gerheim Noronha. 2. ed. Belo Horizonte: Editora UFMG, 2014.

LISPECTOR, Clarice. A paixão segundo G.H.: romance. Rio de Janeiro: Rocco, 2009.

McLUHAN, Marshall. A galáxia de Gutenberg: a formação do homem tipográfico. Tradução de Leônidas Gontijo de Carvalho e Anísio Teixeira. São Paulo: Editora Nacional, Editora da USP, 1972. 
MARQUES, Reinaldo. "O arquivo literário e as imagens do escritor". In:

MARQUES, Reinaldo. Arquivos literários: Teorias, histórias, desafios. Belo Horizonte:

Editora UFMG, 2015. p. 87-114.

McKENZIE, Donald Francis. Bibliografia e Sociologia dos Textos. Tradução de Fernanda

Veríssimo. São Paulo: Editora da Universidade de São Paulo, 2018.

NASCIMENTO, Evando. Retrato desnatural: (diários - 2004 a 2007). Rio de Janeiro: Record, 2008.

PEIRCE, Charles Sanders. Semiótica. 4. ed. Tradução de José Teixeira Coelho Neto. São Paulo: Perspectiva, 2012.

PIGNATARI, Décio. Panteros. Rio de Janeiro: Editora 34, 1992.

PIGNATARI, Décio. Errâncias. São Paulo: Editora SENAC, 2000.

PIGNATARI, Décio. Contracomunicação. 3. Ed. Cotia, SP: Ateliê Editorial, 2004a.

PIGNATARI, Décio. semiótica \& literatura. 6. Ed. Cotia, SP: Ateliê Editorial, 2004b.

PIGNATARI, Décio. Poesia pois époesia: 1950-2000. Cotia, SP: Ateliê Editorial; Campinas, SP: UNICAMP, 2004c.

PIGNATARI, Décio. O rosto da memória. 2. ed. Cotia, SP: Ateliê Editorial, 2014.

RANCIÈRE, Jacques. O destino das imagens. Tradução Mônica Costa Netto; organização Tadeu Capistrano. Rio de Janeiro: Contraponto, 2012.

SELIGMANN-SILVA, Márcio. escrituras da história e da memória. In: SELIGMANN-SILVA, Márcio (Org.). Palavra e imagem: memória e escritura. Chapecó: Argos, 2006, p. 205-225.

STAIGER, Emil. Conceitos Fundamentais da Poética. Tradução de Celeste Aída Galeão. Rio de Janeiro: Tempo Brasileiro, 1977.

SÜSSEKIND, Flora. Rodapés, tratados e ensaios. A formação da crítica literária moderna. In: SÜSSEKIND, Flora. Papéis colados. 2. ed. Rio de Janeiro: Editora UFRJ, 
2002, p. 15-36.

WATT, Ian. $A$ ascensão do romance: estudos sobre Defoe, Richardson e Fielding.

Tradução de Hildergard Feist. São Paulo: Companhia das Letras, 2010.

WINTER, Jay. a geração da memória: reflexões sobre o "boom da memória" nos estudos contemporâneos de história. Tradução de Claudia Valladão de Mattos. In: SELIGMANN-SILVA, Márcio (Org.). Palavra e imagem: memória e escritura. Chapecó: Argos, 2006, p. 67-90.

Submissão: 29/05/2020

Aceite: $30 / 09 / 2020$

https://doi.org/10.5007/2176-8552.2020.e73375

Esta obra foi licenciada com uma Licença Creative Commons Atribuição-NãoComercial 4.0 Internacional. 